\title{
Foodborne Illness Acquired in the United States-Major Pathogens
}

\author{
Elaine Scallan, ${ }^{1}$ Robert M. Hoekstra, Frederick J. Angulo, Robert V. Tauxe, Marc-Alain Widdowson, \\ Sharon L. Roy, Jeffery L. Jones, and Patricia M. Griffin
}

Estimates of foodborne illness can be used to direct food safety policy and interventions. We used data from active and passive surveillance and other sources to estimate that each year 31 major pathogens acquired in the United States caused 9.4 million episodes of foodborne illness (90\% credible interval [Crl] 6.6-12.7 million), 55,961 hospitalizations $(90 \% \mathrm{Crl} 39,534-75,741)$, and 1,351 deaths (90\% Crl 712-2,268). Most (58\%) illnesses were caused by norovirus, followed by nontyphoidal Salmonella spp. (11\%), Clostridium perfringens (10\%), and Campylobacter spp. (9\%). Leading causes of hospitalization were nontyphoidal Salmonella spp. (35\%), norovirus (26\%), Campylobacter spp. (15\%), and Toxoplasma gondii (8\%). Leading causes of death were nontyphoidal Salmonella spp. (28\%), T. gondii (24\%), Listeria monocytogenes (19\%), and norovirus $(11 \%)$. These estimates cannot be compared with prior (1999) estimates to assess trends because different methods were used. Additional data and more refined methods can improve future estimates.

— stimates of the overall number of episodes of foodborne Cillness are helpful for allocating resources and prioritizing interventions. However, arriving at these estimates is challenging because food may become contaminated by many agents (e.g., a variety of bacteria, viruses, parasites, and chemicals), transmission can occur by nonfood mechanisms (e.g., contact with animals or consumption of contaminated water), the proportion of disease transmitted by food differs by pathogen and by host factors (e.g. age and immunity), and only a small proportion of illnesses are confirmed by laboratory testing and reported to public health agencies.

Laboratory-based surveillance provides crucial information for assessing foodborne disease trends. However,

Author affiliation: Centers for Disease Control and Prevention, Atlanta, Georgia, USA

DOI: 10.3201/eid1701.P11101 because only a small proportion of illnesses are diagnosed and reported, periodic assessments of total episodes of illness are also needed. (Hereafter, episodes of illness are referred to as illnesses.) Several countries have conducted prospective population-based or cross-sectional studies to supplement surveillance and estimate the overall number of foodborne illnesses (1). In 2007, the World Health Organization launched an initiative to estimate the global burden of foodborne diseases (2).

In 1999, the Centers for Disease Control and Prevention provided comprehensive estimates of foodborne illnesses, hospitalizations, and deaths in the United States caused by known and unknown agents (3). This effort identified many data gaps and methodologic limitations. Since then, new data and methods have become available. This article is 1 of 2 reporting new estimates of foodborne diseases acquired in the United States (hereafter referred to as domestically acquired). This article provides estimates of major known pathogens; the other provides estimates for agents of acute gastroenteritis not specified in this article (4).

\section{Methods}

Adequate data for preparing national estimates were available for 31 pathogens. We estimated the number of foodborne illnesses, hospitalizations, and deaths caused by these 31 domestically acquired pathogens by using data shown in the online Appendix Table (www.cdc.gov/EID/ content/17/1/7-appT.htm) and online Technical Appendix 1 (www.cdc.gov/EID/content/17/1/7-Techapp1.pdf).

Data were mostly from 2000-2008, and all estimates were based on the US population in 2006 (299 million persons). Estimates were derived from statistical models with many inputs, each with some measure of uncertainty (5). To reflect this uncertainty, we used probability distributions to describe a range of plausible values for all model

${ }^{1}$ Current affiliation: Colorado School of Public Health, Aurora, Colorado, USA. 
inputs. We expressed model outputs as probability distributions summarized by a mean point estimate with $90 \%$ credible intervals (CrIs). We used 2 types of modeling approaches for different types of data: 1) models that began with counts of laboratory-confirmed illnesses and were adjusted for undercounts (because of underreporting and underdiagnosis) and thus scaled up to the estimated number of illnesses and 2) models that began with a US population and used incidence data to scale down to the estimated number of illnesses (Table 1). The modeling approaches used and parameters of these probability distributions are detailed in online Technical Appendixes 2 and 3 (www. cdc.gov/EID/content/17/1/7-Techapp2.pdf and www.cdc. gov/EID/content/17/1/7-Techapp3.pdf, respectively); the proportions cited are modal values.

\section{IIInesses}

Laboratory-based surveillance data were available for 25 pathogens (online Appendix Table). The following events must occur for an illness to be ascertained and included in laboratory-based surveillance: the ill person must seek medical care, a specimen must be submitted for laboratory testing, the laboratory must test for and identify the causative agent, and the illness must be reported to public health authorities. If a break occurs in any of the first 3 steps of this surveillance chain, the causative agent will not be laboratory confirmed (underdiagnosis). Furthermore, although all laboratory-confirmed illnesses are reported by active surveillance, some will not be reported by passive surveillance (underreporting). Therefore, to estimate the number of illnesses caused by pathogens under public health surveillance, we determined the number of laboratory-confirmed illnesses and adjusted for underdiagnosis and, if necessary, for underreporting by using a series of component multipliers.

Laboratory-confirmed illnesses for these 25 pathogens were reported through 5 surveillance programs: the Foodborne Diseases Active Surveillance Network (Food-
Net) for Campylobacter spp., Cryptosporidium spp., Cyclospora cayetanensis, Shiga toxin-producing Escherichia coli (STEC) O157, STEC non-O157, Listeria monocytogenes, nontyphoidal Salmonella spp., Salmonella enterica serotype Typhi, Shigella spp., and Yersinia enterocolitica; the National Notifiable Diseases Surveillance System (NNDSS) for Brucella spp., Clostridium botulinum, Trichinella spp., hepatitis A virus, and Giardia intestinalis; the Cholera and Other Vibrio Illness Surveillance (COVIS) system for toxigenic Vibrio cholerae, $V$. vulnificus, $V$. parahemolyticus, and other Vibrio spp.; the National Tuberculosis Surveillance System (NTSS) for Mycobacterium bovis; and the Foodborne Disease Outbreak Surveillance System (FDOSS) for Bacillus cereus, Clostridium perfringens, enterotoxigenic E. coli (ETEC), Staphylococcus aureus, and Streptococcus spp. group A (online Appendix Table; online Technical Appendix 1). When data were available from $>1$ surveillance system, we used active surveillance data from FoodNet, except for Vibrio spp., for which we used COVIS because of geographic clustering of Vibrio spp. infections outside FoodNet sites. We used data on outbreak-associated illnesses from FDOSS only for pathogens for which no data were available from other systems.

Because FoodNet conducts surveillance at 10 sites (6), we estimated the number of laboratory-confirmed illnesses in the United States by applying incidence from FoodNet to the estimated US population for 2006 (7). We constructed a probability distribution based on extrapolation of rates by year (2005-2008) in each FoodNet site (online Technical Appendix 3). We used data from 2005-2008 because the FoodNet surveillance area was constant during that period and because FoodNet began collecting information on foreign travel in 2004. We used data from 2000-2007 for NNDSS, COVIS, and FDOSS and annual counts of reported illnesses for our probability distributions. Some evidence of trend was found for illness caused by hepatitis A virus, S. aureus, and Vibrio spp.; therefore, recent years were weighted more heavily (online Technical Appendixes

\begin{tabular}{|c|c|c|c|}
\hline \multicolumn{3}{|c|}{ Pathogens for which laboratory-confirmed illnesses were scaled up } & \multirow{2}{*}{$\begin{array}{l}\text { Pathogens for which US } \\
\text { population was scaled down }\end{array}$} \\
\hline Active surveillance data & Passive surveillance data & Outbreak surveillance data & \\
\hline Campylobacter spp. & Brucella spp. & Bacillus cereus & Astrovirus \\
\hline Cryptosporidium spp. & Clostridium botulinum & Clostridium perfringens & Norovirus \\
\hline Cyclospora cayetanensis & Giardia intestinalis & ETEC $\dagger$ & Rotavirus \\
\hline STEC 0157 & Hepatitis A virus & Staphylococcus aureus & Sapovirus \\
\hline STEC non-O157 & Mycobacterium bovis & Streptococcus spp. group A & Toxoplasma gondii \\
\hline Listeria monocytogenes & Trichinella spp. & & \\
\hline Salmonella spp., nontyphoidalł & Vibrio cholera, toxigenic & & \\
\hline S. enterica serotype Typhi & Vibrio parahaemolyticus & & \\
\hline Shigella spp. & Vibrio vulnificus & & \\
\hline Yersinia enterocolitica & Vibrio spp., other & & \\
\hline
\end{tabular}


$2,3)$. NTSS was used to determine the number of reported illnesses caused by M. bovis during 2004-2007.

We assumed that all laboratory-confirmed illnesses were reported to FoodNet active surveillance in the relevant catchment areas. Because COVIS and NNDSS conduct passive surveillance, we applied an underreporting multiplier ( 1.1 for bacteria and 1.3 for parasites) derived by comparing incidence of all nationally notifiable illnesses ascertained through FoodNet with that reported to NNDSS (online Technical Appendix 4, www.cdc.gov/ EID/content/17/1/7-Techapp4.pdf). For the 5 bacteria for which only outbreak data were available, we estimated the number of laboratory-confirmed illnesses by creating an underreporting multiplier as follows. We determined the proportion of illnesses ascertained through FoodNet that were caused by Campylobacter spp., Cryptosporidium spp., C. cayatanensis, L. monocytogenes, Salmonella spp., Shigella spp., STEC, Vibrio spp., and Y. enterocolitica that were also reported to FDOSS as outbreak associated and applied the inverse of this proportion, 25.5, to those pathogens (online Technical Appendix 4). We assumed that all illnesses caused by M. bovis were reported to NTSS.

To adjust for underdiagnosis resulting from variations in medical care seeking, specimen submission, laboratory testing, and test sensitivity, we created pathogen-specific multipliers. To adjust for medical care seeking and specimen submission, we pooled data from FoodNet Population Surveys in 2000-2001, 2002-2003 (8), and 20062007 (Centers for Disease Control and Prevention, unpub. data) from which we estimated the proportion of persons who in the past month reported an acute diarrheal illness ( $\geq 3$ loose stools in 24 hours lasting $>1$ day or resulting in restricted daily activities) and sought medical care and submitted a stool sample for that illness. Because persons with more severe illness are more likely to seek care (9), we estimated pathogen-specific proportions of persons with laboratory-confirmed infections who had severe illness (e.g., bloody diarrhea) and used medical care seeking and stool sample submission rates for bloody $(35 \%$ and $36 \%$, respectively) and nonbloody (18\% and 19\%, respectively) diarrhea as surrogates for severe and mild cases of most illnesses (online Technical Appendix 3). However, for infections with $L$. monocytogenes, $M$. bovis, and $V$. vulnificus and severe infections with hepatitis A virus, we assumed high rates of medical care seeking (i.e., we assumed that $100 \%$ of persons with M. bovis infection and $90 \%$ with L. monocytogenes, $V$. vulnificus, or severe hepatitis A virus infections sought care) and specimen submission $(100 \%$ for hepatitis A virus and M. bovis, $80 \%$ for others). We accounted for percentage of laboratories that routinely tested for specific pathogens $(25 \%-100 \%)$ and test sensitivity $(28 \%-100 \%)$ by using data from FoodNet
$(10,11)$ and other surveys of clinical diagnostic laboratory practices (online Technical Appendix 3). For the 5 pathogens for which data were from outbreaks only, we used the nontyphoidal Salmonella spp. underdiagnosis multiplier.

Alternative approaches were used for infections not routinely reported by any surveillance system (i.e., diarrheagenic E. coli other than STEC and ETEC, T. gondii, astrovirus, rotavirus, sapovirus, and norovirus) (online Technical Appendixes 1-3). We assumed diarrheagenic E. coli other than STEC and ETEC to be as common as ETEC. Illnesses caused by $T$. gondii were estimated by using nationally representative serologic data from the 19992004 National Health and Nutrition Examination Survey (12) and an estimate that clinical illness develops in $15 \%$ of persons who seroconvert (13). We assumed that $75 \%$ of children experience an episode of clinical rotavirus illness by 5 years of age, consistent with findings from other studies (14), and used this estimate for astrovirus and sapovirus. We estimated norovirus illnesses by applying mean proportion of all acute gastroenteritis caused by norovirus $(11 \%)$ according to studies in other industrialized countries $(15-18)$ to estimates of acute gastroenteritis from FoodNet Population Surveys (online Appendix Table; online Technical Appendixes 1-3) (4).

\section{Hospitalizations and Deaths}

For most pathogens, numbers of hospitalizations and deaths were estimated by determining (from surveillance data) the proportion of persons who were hospitalized and the proportion who died and applying these proportions to the estimated number of laboratory-confirmed illnesses (online Appendix Table; online Technical Appendixes 1,3). Rates of hospitalization and death caused by $G$. intestinalis and $T$. gondii were based on the 2000-2006 Nationwide Inpatient Sample. Because some persons with illnesses that were not laboratory confirmed would also have been hospitalized and died, we doubled the number of hospitalizations and deaths to adjust for underdiagnosis, similar to the method used by Mead et al. (3) but applied an uncertainty distribution (online Technical Appendix 3). For diarrheagenic E. coli other than STEC and ETEC, total numbers of hospitalizations and deaths were assumed to be the same as those for ETEC. For rotavirus, we used previous estimates (14). For astrovirus and sapovirus, we assumed that the number was $25 \%$ that of rotavirus $(19,20)$. Numbers of norovirus hospitalizations and deaths were determined by multiplying the estimated number of hospitalizations and deaths caused by acute gastroenteritis, estimated by using national data on outpatient visits resulting in hospitalization, hospital discharge surveys, and death certificates (online Appendix Table; online Technical Appendixes 1-3) 
(4), by the same norovirus proportion (11\%) used to estimate illnesses (15-18).

\section{Domestically Acquired Foodborne IIInesses}

Data from published studies and surveillance were used to determine, for each pathogen, the proportion of illnesses acquired while the person had been traveling outside the United States (online Technical Appendixes 1, 3). The remaining proportion was considered domestically acquired. We based our estimates of the proportion of domestically acquired foodborne illnesses caused by each pathogen on data from surveillance, risk factor studies, and a literature review (online Technical Appendixes 1, 3).

\section{Uncertainty Analysis}

We used empirical data, when available, to define entire distributions or parameters of distributions (online Technical Appendix 3). When data were sparse, we made reasoned judgments based on context, plausibility, and previously published estimates. The parametric distribution used for almost all multipliers was a 4-parameter beta (modified PERT) distribution (21). The first 3 parameters are low, modal, and high. The fourth parameter is related to the variability of the distribution. We typically fixed this last parameter at 4 , which yields the simple PERT distribution (21). However, when describing the outbreak reporting multiplier, we used a value of 20 (online Technical Appendix 4).

Uncertainty in the estimates is the cumulative effect of uncertainty of each of the model inputs. We iteratively generated sets of independent pathogen-specific adjustment factors and used these multipliers to estimate illnesses, hospitalizations, and deaths (Figure; online Technical Appendix 2). On the basis of 100,000 iterations, we obtained empirical distributions of counts corresponding to Bayesian posterior distributions and used these posterior distributions to generate a point estimate (posterior mean) and upper and lower $5 \%$ limits for $90 \%$ CrIs. Because incidence of illnesses differed by location and over time, we included these variations in the models, which led to wider CrIs than if we had assumed that inputs represented independent random samples of a fixed US population. We used SAS version 9.2 (SAS Institute, Cary, NC, USA) for these analyses.

\section{Results}

\section{Foodborne Illnesses}

We estimate that each year in the United States, 31 pathogens caused 37.2 million (90\% CrI 28.4-47.6 million) illnesses, of which 36.4 million (90\% CrI 27.7-46.7 million) were domestically acquired; of these, 9.4 million (90\% CrI 6.6-12.7 million) were foodborne (Table 2; expanded version available online, www.cdc.gov/EID/ content/17/1/7-T2.htm). We estimate that 5.5 million (59\%) foodborne illnesses were caused by viruses, 3.6 million (39\%) by bacteria, and 0.2 million $(2 \%)$ by parasites. The pathogens that caused the most illnesses were norovirus (5.5 million, 58\%), nontyphoidal Salmonella spp. (1.0 million, $11 \%$ ), C. perfringens (1.0 million, $10 \%$ ), and Campylobacter spp. (0.8 million, $9 \%$ ).

\section{Hospitalizations}

We estimate that these 31 pathogens caused 228,744 (90\% CrI 188,326-275,601) hospitalizations annually, of which $55,961(90 \%$ CrI 39,534-75,741) were caused by contaminated food eaten in the United States (Table 3; expanded version available online, www.cdc.gov/EID/ content/17/1/7-T3.htm). Of these, 64\% were caused by bacteria, $27 \%$ by viruses, and $9 \%$ by parasites. The leading causes of hospitalization were nontyphoidal Salmonella spp. (35\%), norovirus (26\%), Campylobacter spp. (15\%), and T. gondii (8\%).

\section{Deaths}

We estimate that these 31 pathogens caused 2,612 deaths $(90 \%$ CrI $1,723-3,819)$, of which $1,351(90 \%$ CrI

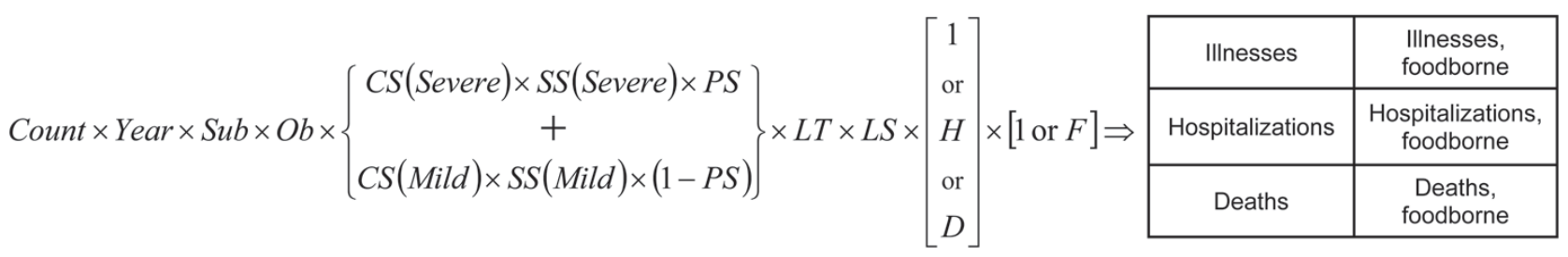

Figure. Example schematic diagram of the estimation and uncertainty model used to estimate episodes of illness, hospitalizations, and deaths in the United States. Count, data (empirical distribution); Year, factor to standardize non-2006 counts to 2006 (constant); Sub, expansive factor to scale area surveillance to the entire US population (constant); Ob, expansive factor to scale outbreak counts up to outbreak plus sporadic counts (beta distribution); CS, expansive factor to scale care seekers to all ill, with severe and mild illness versions (PERT distribution); SS, expansive factor to scale submitted samples to all visits, with severe and mild illness versions (PERT distribution); $P S$, estimated proportion of illnesses that are severe (PERT distribution); $L T$, expansive factor to scale tests performed up to samples submitted (PERT distribution); $L S$, expansive factor to scale positive test results up to true positive specimens (PERT distribution); $H$, contractive factor to scale illnesses down to hospitalized illnesses (PERT distribution); $D$, contractive factor to scale illnesses down to deaths (PERT distribution); $F$, contractive factor to scale illnesses down to foodborne illnesses (PERT distribution). 
$712-2,268)$ were caused by contaminated food eaten in the United States (Table 3). Of these, $64 \%$ were caused by bacteria, $25 \%$ by parasites, and $12 \%$ by viruses. The leading causes of death were nontyphoidal Salmonella spp. (28\%), T. gondii (24\%), L. monocytogenes (19\%), and norovirus $(11 \%)$.

\begin{tabular}{|c|c|c|c|c|c|c|}
\hline \multirow[b]{2}{*}{ Pathogen } & \multirow[b]{2}{*}{$\begin{array}{l}\text { Laboratory } \\
\text { confirmed }\end{array}$} & \multicolumn{2}{|c|}{ Multipliers } & \multirow[b]{2}{*}{$\begin{array}{l}\text { Travel } \\
\text { related, \% }\end{array}$} & \multirow[b]{2}{*}{$\begin{array}{l}\text { Foodborne, } \\
\% \dagger\end{array}$} & \multirow[b]{2}{*}{$\begin{array}{c}\text { Domestically acquired foodborne, } \\
\text { mean }(90 \% \text { credible interval) }\end{array}$} \\
\hline & & $\begin{array}{l}\text { Under- } \\
\text { reporting }\end{array}$ & $\begin{array}{c}\text { Under- } \\
\text { diagnosis }\end{array}$ & & & \\
\hline \multicolumn{7}{|l|}{ Bacteria } \\
\hline Bacillus cereus, foodborne & $85 \ddagger$ & 25.5 & 29.3 & $<1$ & 100 & $63,400(15,719-147,354)$ \\
\hline Brucella spp. & $120 \S$ & 1.1 & 15.2 & 16 & 50 & $839(533-1,262)$ \\
\hline Campylobacter spp. & $43,696 \pi$ & 1.0 & 30.3 & 20 & 80 & $845,024(337,031-1,611,083)$ \\
\hline $\begin{array}{l}\text { Clostridium botulinum, } \\
\text { foodborne }\end{array}$ & $25 \S$ & 1.1 & 2.0 & $<1$ & 100 & $55(34-91)$ \\
\hline $\begin{array}{l}\text { Clostridium perfringens, } \\
\text { foodborne }\end{array}$ & $1,295 \ddagger$ & 25.5 & 29.3 & $<1$ & 100 & $965,958(192,316-2,483,309)$ \\
\hline STEC 0157 & $3,704 \pi$ & 1.0 & 26.1 & 4 & 68 & $63,153(17,587-149,631)$ \\
\hline STEC non-O157 & $1,579 \pi$ & 1.0 & 106.8 & 18 & 82 & $112,752(11,467-287,321)$ \\
\hline ETEC, foodborne & $53 \ddagger$ & 25.5 & 29.3 & 55 & 100 & $17,894(24-46,212)$ \\
\hline $\begin{array}{l}\text { Diarrheagenic E. coli } \\
\text { other than STEC and ETEC }\end{array}$ & 53 & 25.5 & 29.3 & $<1$ & 30 & $11,982(16-30,913)$ \\
\hline Listeria monocytogenes & $808 \pi$ & 1.0 & 2.1 & 3 & 99 & $1,591(557-3,161)$ \\
\hline Mycobacterium bovis & 195ा & 1.0 & 1.1 & 70 & 95 & $60(46-74)$ \\
\hline Salmonella spp., nontyphoidal & $41,930 \pi$ & 1.0 & 29.3 & 11 & 94 & $1,027,561(644,786-1,679,667)$ \\
\hline S. enterica serotype Typhi & $433 \pi$ & 1.0 & 13.3 & 67 & 96 & $1,821(87-5,522)$ \\
\hline Shigella spp. & $14,864 \rrbracket$ & 1.0 & 33.3 & 15 & 31 & $131,254(24,511-374,789)$ \\
\hline $\begin{array}{l}\text { Staphylococcus aureus, } \\
\text { foodborne }\end{array}$ & $323 \ddagger$ & 25.5 & 29.3 & $<1$ & 100 & $241,148(72,341-529,417)$ \\
\hline $\begin{array}{l}\text { Streptococcus spp. group A, } \\
\text { foodborne }\end{array}$ & $15 \ddagger$ & 25.5 & 29.3 & $<1$ & 100 & $11,217(15-77,875)$ \\
\hline Vibrio cholerae, toxigenic & $8 \S$ & 1.1 & 33.1 & 70 & 100 & $84(19-213)$ \\
\hline V. vulnificus & $111 \S$ & 1.1 & 1.7 & 2 & 47 & $96(60-139)$ \\
\hline V. parahaemolyticus & $287 \S$ & 1.1 & 142.4 & 10 & 86 & $34,664(18,260-58,027)$ \\
\hline Vibrio spp., other & $220 \S$ & 1.1 & 142.7 & 11 & 57 & $17,564(10,848-26,475)$ \\
\hline Yersinia enterocolitica & $950 \pi$ & 1.0 & 122.8 & 7 & 90 & $97,656(30,388-172,734)$ \\
\hline Subtotal & & & & & & $3,645,773(2,321,468-5,581,290)$ \\
\hline \multicolumn{7}{|l|}{ Parasites } \\
\hline Cryptosporidium spp. & $7,594 \pi$ & 1.0 & 98.6 & 9 & 8 & $57,616(12,060-166,771)$ \\
\hline Cyclospora cayetanensis & $239 \pi$ & 1.0 & 83.1 & 42 & 99 & $11,407(137-37,673)$ \\
\hline Giardia intestinalis & $20,305 \S$ & 1.3 & 46.3 & 8 & 7 & $76,840(51,148-109,739)$ \\
\hline Toxoplasma gondii & & 1.0 & 0.0 & $<1$ & 50 & $86,686(64,861-111,912)$ \\
\hline Trichinella spp. & $13 \S$ & 1.3 & 9.8 & 4 & 100 & $156(42-341)$ \\
\hline Subtotal & & & & & & $232,705(161,923-369,893)$ \\
\hline \multicolumn{7}{|l|}{ Viruses } \\
\hline Astrovirus & NA & NA & NA & 0 & $<1$ & $15,433(5,569-26,643)$ \\
\hline Hepatitis A virus & $3,576 \S$ & 1.1 & 9.1 & 41 & 7 & $1,566(702-3,024)$ \\
\hline Norovirus & NA & NA & NA & $<1$ & 26 & $5,461,731(3,227,078-8,309,480)$ \\
\hline Rotavirus & NA & NA & NA & 0 & $<1$ & $15,433(5,569-26,643)$ \\
\hline Sapovirus & NA & NA & NA & 0 & $<1$ & $15,433(5,569-26,643)$ \\
\hline Subtotal & & & & & & $5,509,597(3,273,623-8,355,568)$ \\
\hline \multicolumn{6}{|l|}{ Total } & $\begin{array}{c}9,388,075 \\
(6,641,440-12,745,709)\end{array}$ \\
\hline \multicolumn{7}{|c|}{$\begin{array}{l}\text { *All estimates based on US population in 2006. Modal or mean value shown unless otherwise stated; see online Technical Appendix } 3 \\
\text { (www.cdc.gov/EID/content/17/1/7-Techapp3.pdf) for the parameters of these distributions. STEC, Shiga toxin-producing Escherichia coli; ETEC, } \\
\text { enterotoxigenic E. coli; NA, not applicable. An expanded version of this table is available online (www.cdc.gov/EID/content/17/1/7-T2.htm). } \\
\text { tPercentage foodborne among domestically acquired illnesses. } \\
\text { tPassive surveillance data on outbreak-associated illnesses from the Foodborne Disease Outbreak Surveillance System. Estimates based on the number } \\
\text { of foodborne illnesses ascertained in surveillance and therefore assumed to reflect only foodborne transmission. } \\
\text { §Passive surveillance data from Cholera and Other Vibrio Illness Surveillance or the National Notifiable Disease Surveillance System. } \\
\text { TActive surveillance data from Foodborne Diseases Active Surveillance Network, adjusted for geographic coverage; data from the National Tuberculosis } \\
\text { Surveillance System for M. bovis. }\end{array}$} \\
\hline
\end{tabular}




\section{Discussion}

We estimate that foods consumed in the United States that were contaminated with 31 known agents of foodborne disease caused 9.4 million illnesses, 55,961 hospitalizations, and 1,351 deaths each year. Norovirus caused the most illnesses; nontyphoidal Salmonella spp., norovirus, Campylobacter spp., and T. gondii caused the most hospitalizations; and nontyphoidal Salmonella spp., T. gondii, L. monocytogenes, and norovirus caused the most deaths. Scarce data precluded estimates for other known infectious and noninfectious agents, such as chemicals. Foodborne diseases are also caused by agents not yet recognized as being transmitted in food and by unknown agents (22). The numbers of illnesses caused by these unspecified agents are estimated elsewhere (4).

Studies estimating the overall number of foodborne illnesses have been conducted in England and Wales and in Australia $(23,24)$. Similar to our findings, in Australia norovirus was the leading cause of foodborne illness, accounting for $30 \%$ of illnesses caused by known pathogens.

Table 3. Estimated annual number of domestically acquired foodborne hospitalizations and deaths caused by 31 pathogens, United States*

\begin{tabular}{|c|c|c|c|c|}
\hline Pathogen & $\begin{array}{l}\text { Hospitalization } \\
\text { rate, } \% \dagger\end{array}$ & $\begin{array}{l}\text { Hospitalizations, mean } \\
(90 \% \text { credible interval) }\end{array}$ & $\begin{array}{l}\text { Death } \\
\text { rate, \%† }\end{array}$ & $\begin{array}{c}\text { Deaths, mean } \\
(90 \% \text { credible interval) }\end{array}$ \\
\hline \multicolumn{5}{|l|}{ Bacteria } \\
\hline Bacillus cereus, foodborne & 0.4 & $20(0-85)$ & 0 & 0 \\
\hline Brucella spp. & 55.0 & $55(33-84)$ & 0.9 & $1(0-2)$ \\
\hline Campylobacter spp. & 17.1 & $8,463(4,300-15,227)$ & 0.1 & $76(0-332)$ \\
\hline Clostridium botulinum, foodborne $\neq$ & 82.6 & $42(19-77)$ & 17.3 & $9(0-51)$ \\
\hline Clostridium perfringens, foodborne $\ddagger$ & 0.6 & $438(44-2,008)$ & $<0.1$ & $26(0-163)$ \\
\hline STEC 0157 & 46.2 & $2,138(549-4,614)$ & 0.5 & $20(0-113)$ \\
\hline STEC non-O157 & 12.8 & $271(0-971)$ & 0.3 & $0(0-0) \S$ \\
\hline ETEC, foodborne & 0.8 & $12(0-53)$ & 0 & 0 \\
\hline Diarrheagenic E. coli other than STEC and ETEC & 0.8 & $8(0-36)$ & 0 & 0 \\
\hline Listeria monocytogenes & 94.0 & $1,455(521-3,018)$ & 15.9 & $255(0-733)$ \\
\hline Mycobacterium bovis & 55.0 & $31(21-42)$ & 4.7 & $3(2-3)$ \\
\hline Salmonella spp., nontyphoidal & 27.2 & $19,336(8,545-37,490)$ & 0.5 & $378(0-1,011)$ \\
\hline Shigella spp. & 20.2 & $1,456(287-3,695)$ & 0.1 & $10(0-67)$ \\
\hline Staphylococcus aureus, foodborne $\neq$ & 6.4 & $1,064(173-2,997)$ & $<0.1$ & $6(0-48)$ \\
\hline Streptococcus spp. group A, foodborneł & 0.2 & $1(0-6)$ & 0 & 0 \\
\hline Vibrio cholerae, toxigenic & 43.1 & $2(0-5)$ & 0 & 0 \\
\hline V. vulnificus & 91.3 & $93(53-145)$ & 34.8 & $36(19-57)$ \\
\hline V. parahaemolyticus & 22.5 & $100(50-169)$ & 0.9 & $4(0-17)$ \\
\hline Vibrio spp., other & 37.1 & $83(51-124)$ & 3.7 & $8(3-19)$ \\
\hline Yersinia enterocolitica & 34.4 & $533(0-1,173)$ & 2.0 & $29(0-173)$ \\
\hline Subtotal & & $35,796(21,519-53,414)$ & & $861(260-1,761)$ \\
\hline \multicolumn{5}{|l|}{ Parasites } \\
\hline Cryptosporidium spp. & 25.0 & $210(58-518)$ & 0.3 & $4(0-19)$ \\
\hline Cyclospora cayetanensis & 6.5 & $11(0-109)$ & 0.0 & 0 \\
\hline Giardia intestinalis & 8.8 & $225(141-325)$ & 0.1 & $2(1-3)$ \\
\hline Toxoplasma gondii & 2.6 & $4,428(2,634-6,674)$ & 0.2 & $327(200-482)$ \\
\hline \multicolumn{5}{|l|}{ Viruses } \\
\hline Astrovirus & 0.4 & $87(32-147)$ & $<0.1$ & 0 \\
\hline Hepatitis A virus & 31.5 & $99(42-193)$ & 2.4 & $7(3-15)$ \\
\hline Norovirus & 0.03 & $14,663(8,097-23,323)$ & $<0.1$ & $149(84-237)$ \\
\hline Rotavirus & 1.7 & $348(128-586)$ & $<0.1$ & 0 \\
\hline Sapovirus & 0.4 & $87(32-147)$ & $<0.1$ & 0 \\
\hline Subtotal & & $15,284(8,719-23,962)$ & & $157(91-245)$ \\
\hline Total & & $55,961(39,534-75,741)$ & & $1,351(712-2,268)$ \\
\hline
\end{tabular}

*All estimates were based on US population in 2006. STEC, Shiga toxin-producing Escherichia coli; ETEC, enterotoxigenic E. coli. An expanded version of this table is available online (www.cdc.gov/EID/content/17/1/7-T3.htm).

†For laboratory-confirmed illnesses. Unadjusted hospitalization and death rates are presented here. These rates were doubled to adjust for underdiagnosis before being applied to the number of laboratory-confirmed cases to estimate the total number of hospitalizations and deaths. The hospitalization and death rates for astrovirus, norovirus, rotavirus, and sapovirus presented here are the percentage of total estimated illness and were not subject to further adjustment.

$\ddagger$ Estimates based on the number of foodborne illnesses ascertained in surveillance, therefore assumed to reflect only foodborne transmission. $\S$ We report median values instead of means for the distributions of deaths caused by STEC non-O157 because of extremely skewed data. 
In England and Wales, norovirus accounted for only 8\% of known foodborne illnesses; however, stool sample reexamination using molecular techniques documented higher rates (18). Nontyphoidal Salmonella spp. and Campylobacter spp. were leading causes of foodborne illnesses in all 3 countries (England and Wales, Australia, and the United States), although nontyphoidal Salmonella spp. accounted for a greater proportion of illness in the United States. Recent serologic data from Europe suggest that Salmonella spp. infections are more common than estimated by our methods; however, many infections may be asymptomatic (25). Our estimates did not capture mild illnesses associated with some pathogens. For example, mild cases of botulism are often recognized as part of outbreaks, but affected persons seldom seek medical care and are not captured by surveillance except during outbreaks $(26,27)$. Likewise, $L$. monocytogenes is rarely diagnosed as the cause of gastroenteritis and fever, partly because this organism is not detected by routine stool culture (28). Early spontaneous abortion or miscarriage associated with listeriosis may also be underdiagnosed.

Accurately estimating hospitalizations and deaths caused by foodborne pathogens is particularly challenging. National data on outpatient visits resulting in hospitalization, hospital discharges, and death certificates probably substantially underestimate pathogen-specific cases because for pathogen-specific diagnoses to be recorded, health care providers must order the appropriate diagnostic tests and coding must be accurate. Particularly in vulnerable populations, dehydration or electrolyte imbalance from a gastrointestinal illness may exacerbate a chronic illness, resulting in hospitalization or death well after resolution of the gastrointestinal illness; thus, the gastrointestinal illness may not be coded as a contributing factor. Moreover, if a pathogen is not detected, infections may be coded as noninfectious illnesses (29). For norovirus, we estimated the number of hospitalizations and deaths by applying the estimated proportion of acute gastroenteritis illnesses caused by norovirus to overall estimates of hospitalizations and deaths from acute gastroenteritis; this choice is supported by studies of hospitalizations for norovirus $(30,31)$. For most other pathogens, we used data from surveillance to estimate pathogen-specific hospitalizations and deaths and doubled the numbers to adjust for underdiagnosis. More precise information about the degree of undercounting of hospitalizations and deaths for each pathogen would improve these estimates.

Our methods and data differed from those used for the 1999 estimates (3). Our estimate of medical care seeking among persons with a diarrheal illness, derived from the 3 most recent FoodNet Population Surveys conducted during 2000-2007, was higher than that estimated from the 1996-1997 FoodNet Population Survey used for the
1999 estimates (35\% and 18\% among persons reporting bloody and nonbloody diarrhea, respectively, compared with $15 \%$ and $12 \%$ in the earlier [1999] study) (8). These data resulted in lower underdiagnosis multipliers, which contributed to lower estimates of number of illnesses. The biggest change from the earlier estimate was the estimated number of norovirus illnesses, which decreased for 2 reasons. First, the number of acute gastrointestinal illnesses estimated from the FoodNet Population Survey and used in the current study was lower than the estimated number of acute gastrointestinal illnesses used in the 1999 assessment. The earlier study used data from 1996-1997; the sample size was one fifth as large as ours and incorporated data from US studies conducted before $1980(32,33)$. Both estimates excluded persons reporting concurrent cough or sore throat, but the proportion of persons reporting these signs and symptoms was higher in the FoodNet Population Surveys we used than that in the older US studies ( $38 \%$ vs. $25 \%$ ), contributing to a lower estimated prevalence of acute gastroenteritis ( 0.60 vs. 0.79 episodes/ person/year) (4,32,33). Additionally, the current study excluded persons with vomiting who were ill for $<1$ day or whose illness did not result in restricted daily activities, whereas the earlier study included all vomiting episodes. These factors contributed to the new estimate of acute gastroenteritis being $24 \%$ lower than the earlier estimate, more likely the result of increased accuracy than a true decrease in illnesses (4). Second, the lower current estimate for norovirus illnesses resulted from a lower proportion of norovirus estimated to be foodborne (decreased from $40 \%$ to $26 \%$ ); this lower proportion is similar to that estimated in recent studies from other countries $(23,24)$. Because of these reasons and use of other data sources and methods, our estimate cannot be compared with the 1999 estimate for the purpose of assessing trends. FoodNet provides the best data on trends over time (34).

Data used in the current study came from a variety of sources and were of variable quality and representativeness. FoodNet sites, from which we used data for 10 pathogens, are not completely representative of the US population, but 1 study indicated that demographic data from FoodNet and from the 2005 US census did not differ much (6). For 5 pathogens, only data on foodborne outbreak-related cases were available. No routine surveillance data were available for most viruses, forcing us to use a different modeling approach for viruses than for most other pathogens. Given the large number of norovirus illnesses in these estimates, the paucity of supporting data is a major limitation. Moreover, combining different methods is not optimal because methods themselves may affect the estimates. We chose our modeling approach and used the PERT distribution for many inputs because data were sometimes limited and subjective decisions were required. Other investigators could 
have chosen other distributions, for good reasons, and arrived at different estimates.

Our assumptions about the proportion of illnesses transmitted by food profoundly affect our estimates, but data on which to base these estimates were often lacking. We used data from surveillance, risk factor studies, and the current literature to estimate the proportion of pathogenspecific illnesses caused by consumption of contaminated food (35), but it is not known how representative these data are of total illnesses and whether the foodborne proportion is similar across age groups. For example, the proportion of some illnesses acquired from animals (e.g., STEC O157) may be higher among children than adults (36), and the proportions that spread person-to-person (e.g., norovirus) may be higher among institutionalized elderly persons (37). Because a higher proportion of cases are reportedly associated with hospitalization or death in these vulnerable groups, we may have overestimated the total contribution of foodborne transmission for these outcomes.

The methods used for this study could be adapted to estimate the proportion of illnesses attributable to other modes of transmission, such as waterborne and direct animal contact. The estimates from this study can be used to help direct policy and interventions; to conduct other analyses (e.g., evaluation of economic cost of these diseases and attribution to various food commodities); and as a platform for developing estimates of effects of disease caused by sequelae of foodborne infections.

\section{Acknowledgments}

We thank Tracy Ayers, Michael J. Beach, John Besser, Elizabeth Bosserman, Christopher R Braden, Anthony E. Fiore, Kelly A. Jackson, Rebecca Hall, Erin Hedican, Barbara L. Herwaldt, Scott D. Holmberg, Martha Iwamoto, Philip LoBue, Michael F. Lynch, Eric D. Mintz, John A. Painter, Ian T. Williams, Patricia A. Yu, and David L. Swerdlow for providing data and expert advice for these estimates. We also thank Barbara Mahon for reviewing the manuscript and the anonymous reviewers for helpful suggestions.

Dr Scallan is assistant professor in the Department of Epidemiology at the Colorado School of Public Health. Her research focuses on the burden and attribution of foodborne diseases.

\section{References}

1. Flint JA, Van Duynhoven YT, Angulo FJ, DeLong SM, Braun $\mathrm{P}$, Kirk M, et al. Estimating the burden of acute gastroenteritis, foodborne disease, and pathogens commonly transmitted by food: an international review. Clin Infect Dis. 2005;41:698-704. DOI: $10.1086 / 432064$

2. Kuchenmuller T, Hird S, Stein C, Kramarz P, Nanda A, Havelaar AH. Estimating the global burden of foodborne diseases - a collaborative effort. Euro Surveill. 2009;14:pii:19195.
3. Mead PS, Slutsker L, Dietz V, McCaig LF, Bresee JS, Shapiro C, et al. Food-related illness and death in the United States. Emerg Infect Dis. 1999;5:607-25. DOI: 10.3201/eid0505.990502

4. Scallan E, Griffin PM, Angulo FJ, Tauxe RV, Hoekstra RM. Foodborne illness acquired in the United States-unspecified agents. Emerg Infect Dis. 2011;17:16-22.

5. Powell M, Ebel E, Schlosser W. Considering uncertainty in comparing the burden of illness due to foodborne microbial pathogens. Int J Food Microbiol. 2001;69:209-15. DOI: 10.1016/S0168-1605 (01)00495-0

6. Scallan E. Activities, achievements, and lessons learned during the first 10 years of the Foodborne Diseases Active Surveillance Network: 1996-2005. Clin Infect Dis. 2007;44:718-25.

7. US Census Bureau. Population estimates [cited 2010 March 9]. http://www.census.gov/popest/states/NST-ann-est.html

8. Jones TF, McMillian MB, Scallan E, Frenzen PD, Cronquist AB, Thomas S, et al. A population-based estimate of the substantial burden of diarrhoeal disease in the United States; FoodNet, 1996-2003. Epidemiol Infect. 2007;135:293-301.

9. Scallan E, Jones TF, Cronquist A, Thomas S, Frenzen P, Hoefer D, et al. Factors associated with seeking medical care and submitting a stool sample in estimating the burden of foodborne illness. Foodborne Pathog Dis. 2006;3:432-8. DOI: 10.1089/fpd.2006.3.432

10. Voetsch AC, Angulo FJ, Rabatsky-Ehr T, Shallow S, Cassidy M, Thomas SM, et al. Laboratory practices for stool-specimen culture for bacterial pathogens, including Escherichia coli O157:H7, in the FoodNet sites, 1995-2000. Clin Infect Dis. 2004;38(Suppl 3):S190-7. DOI: $10.1086 / 381586$

11. Jones JL, Lopez A, Wahlquist SP, Nadle J, Wilson M. Survey of clinical laboratory practices for parasitic diseases. Clin Infect Dis. 2004;38(Suppl 3):S198-202. DOI: 10.1086/381587

12. Jones JL, Kruszon-Moran D, Sanders-Lewis K, Wilson M. Toxoplasma gondii infection in the United States, 1999-2004, decline from the prior decade. Am J Trop Med Hyg. 2007;77:405-10.

13. World Health Organization. Toxoplasmosis. Technical report series no. 431. Geneva: The Organization; 1969.

14. Widdowson MA, Meltzer MI, Zhang X, Bresee JS, Parashar UD, Glass RI. Cost-effectiveness and potential impact of rotavirus vaccination in the United States. Pediatrics. 2007;119:684-97.

15. Wheeler JG, Sethi D, Cowden JM, Wall PG, Rodrigues LC, Tompkins DS, et al. Study of infectious intestinal disease in England: rates in the community, presenting to general practice, and reported to national surveillance. The Infectious Intestinal Disease Study Executive. BMJ. 1999;318:1046-50.

16. de Wit MA, Koopmans MP, Kortbeek LM, Wannet WJ, Vinje J, van Leusden F, et al. Sensor, a population-based cohort study on gastroenteritis in the Netherlands: incidence and etiology. Am J Epidemiol. 2001;154:666-74. DOI: 10.1093/aje/154.7.666

17. Marshall JA, Hellard ME, Sinclair MI, Fairley CK, Cox BJ, Catton $\mathrm{MG}$, et al. Incidence and characteristics of endemic Norwalk-like virus-associated gastroenteritis. J Med Virol. 2003;69:568-78. DOI: 10.1002/jmv. 10346

18. Amar CF, East CL, Gray J, Iturriza-Gomara M, Maclure EA, McLauchlin J. Detection by PCR of eight groups of enteric pathogens in 4,627 faecal samples: re-examination of the English casecontrol Infectious Intestinal Disease Study (1993-1996). Eur J Clin Microbiol Infect Dis. 2007;26:311-23.

19. Dennehy PH, Nelson SM, Spangenberger S, Noel JS, Monroe SS, Glass RI. A prospective case-control study of the role of astrovirus in acute diarrhea among hospitalized young children. J Infect Dis. 2001;184:10-5.

20. Klein EJ, Boster DR, Stapp JR, Wells JG, Qin X, Clausen CR, et al. Diarrhea etiology in a children's hospital emergency department: a prospective cohort study. Clin Infect Dis. 2006;43:807-13. DOI: $10.1086 / 507335$ 
21. Vose D. Risk analysis. A quantitative guide. 2nd ed. Chichester (UK): John Wiley \& Sons; 2000

22. Tauxe RV. Emerging foodborne pathogens. Int J Food Microbiol. 2002;78:31-41. DOI: 10.1016/S0168-1605(02)00232-5

23. Adak GK, Meakins SM, Yip H, Lopman BA, O’Brien SJ. Disease risks from foods, England and Wales, 1996-2000. Emerg Infect Dis. 2005;11:365-72.

24. Hall G, Kirk MD, Becker N, Gregory JE, Unicomb L, Millard G, et al. Estimating foodborne gastroenteritis, Australia. Emerg Infect Dis. 2005; 11:1257-64.

25. Simonsen J, Teunis P, Van Pelt W, Van Duynhoven Y, Krogfelt KA, Sadkowska-Todys M, et al. Usefulness of seroconversion rates for comparing infection pressures between countries. Epidemiol Infect. 2010; Apr 12:1-8 [Epub ahead of print].

26. St Louis ME, Peck SH, Bowering D, Morgan GB, Blatherwick J, Banerjee S, et al. Botulism from chopped garlic: delayed recognition of a major outbreak. Ann Intern Med. 1988;108:363-8.

27. Sobel J, Malavet M, John S. Outbreak of clinically mild botulism type E illness from home-salted fish in patients presenting with predominantly gastrointestinal symptoms. Clin Infect Dis. 2007;45:e14-6. DOI: $10.1086 / 518993$

28. Dalton CB, Austin CC, Sobel J, Hayes PS, Bibb WF, Graves LM, et al. An outbreak of gastroenteritis and fever due to Listeria monocytogenes in milk. N Engl J Med. 1997;336:100-5. DOI: 10.1056/ NEJM199701093360204

29. Pinner RW, Teutsch SM, Simonsen L, Klug LA, Graber JM, Clarke MJ, et al. Trends in infectious diseases mortality in the United States. JAMA. 1996;275:189-93.

30. Patel MM, Widdowson MA, Glass RI, Akazawa K, Vinje J, Parashar UD. Systematic literature review of role of noroviruses in sporadic gastroenteritis. Emerg Infect Dis. 2008;14:1224-31.

31. Jansen A, Stark K, Kunkel J, Schreier E, Ignatius R, Liesenfeld O, et al. Aetiology of community-acquired, acute gastroenteritis in hospitalised adults: a prospective cohort study. BMC Infect Dis. 2008;8:143. DOI: $10.1186 / 1471-2334-8-143$
32. Badger GF, Curtiss C, Dingle JH, Hodges RG, Jordan WS Jr, McCorkle LP. A study of illness in a group of Cleveland families. XI. The occurrence of gastrointestinal symptoms. Am J Hyg. 1956;64:349-56.

33. Monto AS, Koopman JS. The Tecumseh Study. XI. Occurrence of acute enteric illness in the community. Am J Epidemiol. 1980;112:323-33.

34. Centers for Disease Control and Prevention. Preliminary FoodNet data on the incidence of infection with pathogens transmitted commonly through food - 10 states, 2009. MMWR Morb Mortal Wkly Rep. 2010;59:418-22.

35. Pires SM, Evers EG, van Pelt W, Ayers T, Scallan E, Angulo FJ, et al. Attributing the human disease burden of foodborne infections to specific sources. Foodborne Pathog Dis. 2009;6:417-24.

36. Crump JA, Sulka AC, Langer AJ, Schaben C, Crielly AS, Gage R, et al. An outbreak of Escherichia coli O157:H7 infections among visitors to a dairy farm. N Engl J Med. 2002;347:555-60. DOI: 10.1056/ NEJMoa020524

37. Blanton LH, Adams SM, Beard RS, Wei G, Bulens SN, Widdowson MA, et al. Molecular and epidemiologic trends of caliciviruses associated with outbreaks of acute gastroenteritis in the United States, 2000-2004. J Infect Dis. 2006;193:413-21. DOI: 10.1086/499315

Address for correspondence: Elaine Scallan, Department of Epidemiology, Colorado School of Public Health, Mailstop B119, Rm W3146, UCDAMC Bldg 500, 13001 E 17th Pl, Aurora, CO 80045, USA; email: elaine. scallan@ucdenver.edu

The opinions expressed by authors contributing to this journal do not necessarily reflect the opinions of the Centers for Disease Control and Prevention or the institutions with which the authors are affiliated.

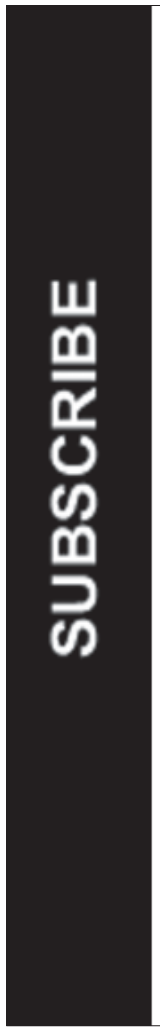

\section{EMERGING} INFECTIOUS DISEASES

$\square$ YES, I would like to receive Emerging Infectious Diseases. Please add me to your mailing list.

Return:

Email: eideditor@cdc.gov

Fax: 404 639-1954

Mail to:

EID Editor

$\mathrm{CDC} / \mathrm{NCID} / \mathrm{MS} \mathrm{D} 61$

1600 Clifton Rd, NE

Atlanta, GA 30333
Number on mailing label:(required)

Name:

Full mailing address: (BLOCK LETTERS)

Full text free online at www.cdc.gov/eid 